\title{
Osteoarthritis in the elderly: clinical and radiological findings in 79 and 85 year olds
}

\author{
E Bagge, A Bjelle, S Edén, A Svanborg
}

\begin{abstract}
The prevalence of joint complaints and clinical and radiological findings of osteoarthritis in wrist, hand, and knee joints was studied in representative population subsamples of 79 and 85 year olds. Joint complaints, clinical findings of osteoarthritis, and radiographic osteoarthritis were more common in women. Age related differences in the prevalence of osteoarthritis were not found. Although there was a correlation between clinical signs of osteoarthritis and radiographic osteoarthritis, clinical signs were often present without radiographic evidence and moderate and severe radiographic osteoarthritis was often present without clinical signs.
\end{abstract}

Epidemiological studies have shown an increased prevalence of osteoarthritis with increasing age. ${ }^{1-8}$ Age is regarded as one of the main causative factors of osteoarthritis. ${ }^{9}$ Most studies have dealt with subjects under the age of 70 , however, and data about osteoarthritis in the older age group are still sparse. ${ }^{23781011}$ There is conflicting evidence as to whether the prevalence of osteoarthritis continues to increase with advancing age. ${ }^{1357}$

A study of elderly people in Göteborg offered unique opportunities to study different aspects of aging in large, well defined, representative population samples. ${ }^{12-14}$ To study whether osteoarthritis increases progressively with advancing age the prevalence of clinical and radiographic osteoarthritis was studied in two cohorts of 79 and 85 year olds within the framework of this population survey.

Department of

Rheumatology,

University of Göteborg, Göteborg, Sweden

E Bagge

A Bjelle

Department of Geriatric and Long-Term Care

Medicine,

University of Göteborg,

Göteborg, Sweden

$S$ Edén

Geriatric Section,

Department of Medicine,

University of Illinois

at Chicago, USA

A Svanborg

Correspondence to:

Dr Eva Bagge,

Department of

Rheumatology,

Sahlgrens Hospital,

$S \rightarrow 41345$ Göteborg,

Sweden

Accepted for publication

12 July 1990

\section{Study population and methods STUDY POPULATION}

The longitudinal study of the elderly in Göteborg started in 1971-72 with a representative sample of $30 \%$ of the 70 year old population (cohort I). The survivors of this first cohort were followed up at the ages of $75,79,81,83$, and 85 . In $1986 / 1987$, at the re-examination of the surviving 85 year olds of the first cohort, all 85 year olds in Göteborg were invited to take part in the examination, resulting in a total sample of 974 85 year olds ( 302 men, 672 women; participation rate $70 \%$ ). Among these, 260 probands (75 cohort.

In 1976-77 a new representative sample of 70 year olds (cohort II) was examined. The 538 survivors of this second cohort were re-examined men, 185 women) belonged to the original first at the ages of 75 and 79 (220 men, 318 women; participation rate $82 \%$ ). Our study deals with a subsample of the 79 year olds from cohort II and a subsample of 85 year olds, including survivors of the original first cohort and 85 year olds invited and examined for the first time.

\section{SAMPLING}

The design and sampling have previously been described ${ }^{12-14}$ in detail. In summary, the sample of 70 year olds (cohort I) in 1971-72 was consecutively assigned numbers from 1 to 5 in order to permit subsampling. These 'proband figures' were unchanged throughout the longitudinal study. The last invited 85 year olds were assigned numbers 11 to 13 . All 85 year olds were interviewed about joint complaints. Probands numbered 3,5 , and 13 were selected for clinical joint examination and radiographic examination of the wrists, hands, and knee joints. In this report only the interviews on the probands selected for joint examination are referred to.

Similarly, the second cohort was numbered 6 to 10 . Subsamples given the number 10 were selected for an interview about joint complaints and a clinical joint examination. Probands numbered 8,9 , and 10 were selected for radiographic examination of the wrist, hand, and knee joints (table 1).

\section{INTERVIEW AND CLINICAL JOINT EXAMINATION}

All interviews and clinical joint examinations of the selected probands were performed by EB. All were asked: 'Have you now or at any time had any problems with your joints?'. An affirmative response was followed by a more detailed questionnaire, with special emphasis on specific symptoms of probable osteoarthritis in wrist, hand, and knee joints - that is, joint pain, joint stiffness after a period of inactivity, pain upon joint loading, or worsening of pain by or after joint loading. No questions about complaints from individual finger joints or groups of joints were asked. Furthermore, no questions were asked on handedness.

Irrespective of the interview response the probands underwent a clinical joint examination. Symptoms and signs of osteoarthritis in hand, wrist, and knee joints are included in this report. Twelve of the 79 year old probands and 17 of the 85 year olds could only be examined in their homes, nursing homes, or hospitals and did not have a radiographic evaluation. Furthermore, owing to insufficient communication with some probands, 10 of the 79 year olds and 
Table 1 Joint study subsamples of two cohorts aged 79 and 85 years

\begin{tabular}{|c|c|c|c|c|c|c|}
\hline & \multicolumn{3}{|c|}{79 Year olds (cohort II) } & \multicolumn{3}{|c|}{85 Year olds (cohort I) } \\
\hline & Women & Men & Total & Women & Men & Total \\
\hline $\begin{array}{l}\text { Interviewed and clinically examined } \\
\text { Radiographically examined } \\
\text { Clinically and radiographically examined }\end{array}$ & $\begin{array}{r}64 \\
162 \\
\text { d } 51\end{array}$ & $\begin{array}{r}42 \\
104 \\
33\end{array}$ & $\begin{array}{r}106 \\
266 \\
84\end{array}$ & $\begin{array}{r}80 \\
104 \\
48\end{array}$ & $\begin{array}{l}31 \\
58 \\
28\end{array}$ & $\begin{array}{r}111 \\
162 \\
76\end{array}$ \\
\hline
\end{tabular}

18 of the 85 year olds, who visited the outpatient department for the interview and the clinical examination, did not take part in the radiographic examination (table 1). There was no evidence, however, that the vitality and state of health of the non-examined probands differed from that of the radiographically examined ones.

\section{RADIOGRAPHIC TECHNIQUES}

Wrists, hands, and knees were radiographed in posteroanterior projections. Radiographs of the knee joints were taken in the standing position with slight flexion. Kodak X-omatic regular film was used, together with Agfa Geavert screens, with tube potential $35 \mathrm{kV}$ and tube filtration $2 \mathrm{~mm} \mathrm{AL}$.

\section{EXAMINATION OF RADIOGRAPHS}

All radiographs were examined by one observer (EB). Radiological findings in wrist and hand joints on each side were recorded separately in the following eight groups: distal interphalangeal (DIP), proximal interphalangeal (PIP), interphalangeal I (IP I), metacarpophalangeal I (MCP I), MCP II-V, carpometacarpal I (CMC I), intracarpal, and radiocarpal. Osteoarthritis of the left and right side was recorded separately. Osteoarthritic grade was determined by its severity in the most affected joint within each group of joints.

In a separate interobserver study 50 radiographs of wrist, hand, and knee joints were examined by two different observers (EB and Hans Valkenburg). The interobserver agreement was $87 \%$ for osteoarthritis of wrists and hand joints and $91 \%$ for osteoarthritis of knee joints. Thirty radiographs were also re-examined (by EB) after four months. The intraobserver agreement was $\mathbf{9 4 \%}$ for wrist and hand joints and $92 \%$ for knee joints.

CRITERIA

Clinical signs of osteoarthritis

Clinical signs of osteoarthritis in the hands were defined by nodular swelling on the dorsal aspect or periarticular enlargement on one or both of

Table 2 Prevalence (percentage) of patients with joint complaints

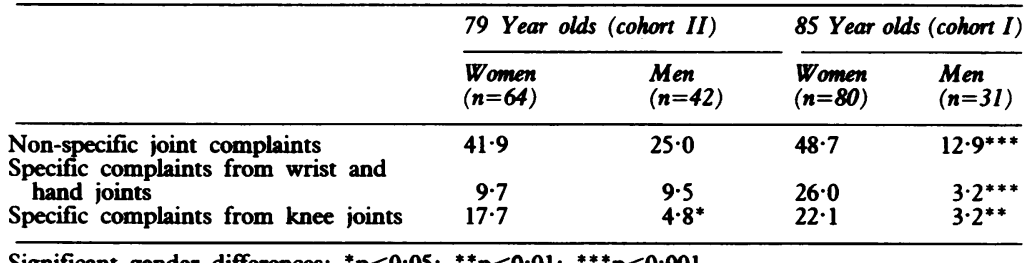

gender differences; ${ }^{*} \mathrm{p}<0.05 ;{ }^{* *} \mathrm{p}<0.01 ;{ }^{* * *} \mathrm{p}<0.001$

No significant cohort differences were noted. the lateral aspects of the DIP and PIP joints, or both; palpable enlargement or instability in the IP I and the MCP I joints, or both; and palpable enlargement or 'squaring' of the CMC I joints, or both. In the knee joints presence of either varus or valgus deformity of any degree, crepitus on active or passive motion, and limitation of range of motion were regarded as clinical signs of osteoarthritis. No criteria for clinical signs of osteoarthritis in the wrists were available.

\section{Radiographic osteoarthritis}

The radiographs were read for osteoarthritis using the Atlas of Standard Radiographs. ${ }^{15}$ Osteoarthritis was graded on a five point scale: $0=$ absent, $1=$ doubtful, $2=$ minimal, $3=$ moderate, and $4=$ severe. Osteoarthritis was defined as grade 2 changes (definite osteophytes) or higher.

\section{STATISTICS}

To study the effects of age and sex analysis of variance (ANOVA) was used. This test was followed by the $\chi^{2}$ test or two non-parametric tests-the Pitman test and the Fisher two tailed test for individual comparisons. Significance of differences between left and right side in each group of joints was calculated by $\chi^{2}$ tests. A $\mathrm{p}$ value of $<0.01$ was considered significant. To test the overall side differences the sum of the grade of osteoarthritis in each group of hand and wrist joints was calculated and the differences between left and right side tested using the paired $t$ test. When the associations between radiographic osteoarthritis in the hand and wrist joints and complaints and clinical findings, respectively, were tested, the highest radiographic grade of osteoarthritis in hand and wrist joints of the left and right side was used in the analysis. This sum of osteoarthritic grade in wrist and hand joints was also used in the analysis of radiographic osteoarthritis by cohort and gender.

\section{Results}

JOINT COMPLAINTS

There were no significant differences in the prevalence of joint complaints between the 79 year olds of cohort II and the $\mathbf{8 5}$ year olds of cohort I (table 2). Both general joint complaints and specific complaints from wrist, hand, and knee joints were generally more prevalent in women than in men $(p<0.001$, ANOVA). For each cohort the gender difference was significant for general joint complaints and specific complaints from wrists and hands in 85 year olds ( $p<0.001)$ and from knee joints in both 79 and 85 year olds $(p<0.05$ and 0.01 respectively).

\section{CLINICAL SIGNS OF OSTEOARTHRITIS}

The prevalence of clinical signs of osteoarthritis did not differ significantly between 79 and 85 year olds (table 3 ). Women had in general significantly more clinical signs of osteoarthritis than men ( $p<0.01$, ANOVA). Gender differences for clinical signs in individual joints or groups of joints were only noted in the DIP 
Table 3 Prevalence (percentage) of clinical signs of osteoarthritis

\begin{tabular}{|c|c|c|c|c|}
\hline \multirow[t]{2}{*}{ Foint } & \multicolumn{2}{|c|}{79 Year olds (cohort I) } & \multicolumn{2}{|c|}{85 Year olds (cohort I) } \\
\hline & $\begin{array}{l}\text { Women } \\
(n=64)\end{array}$ & $\begin{array}{l}\text { Men } \\
(n=42)\end{array}$ & $\begin{array}{c}\text { Women } \\
(n=80)\end{array}$ & $\begin{array}{l}\text { Men } \\
(n=31)\end{array}$ \\
\hline $\begin{array}{l}\text { Hand } \\
\text { DIPt } \\
\text { PIPt } \\
\text { IPt I } \\
\text { MCP+ I } \\
\text { CMC+ I }\end{array}$ & $\begin{array}{r}39 \cdot 3 \\
30 \cdot 0 \\
11 \cdot 0 \\
29 \cdot 6 \\
4 \cdot 6\end{array}$ & $\begin{array}{c}22.5^{*} \\
31.7 \\
7.1 \\
35.9 \\
3.9\end{array}$ & $\begin{array}{l}40 \cdot 5 \\
30 \cdot 4 \\
12 \cdot 5 \\
30 \cdot 0 \\
10 \cdot 0\end{array}$ & $\begin{array}{r}36 \cdot 6 \\
43 \cdot 3 \\
3 \cdot 4 \\
22 \cdot 6 \\
4 \cdot 8\end{array}$ \\
\hline $\begin{array}{l}\text { Knee } \\
\text { Deformity } \\
\text { Crepitus } \\
\text { Loss of ROM† }\end{array}$ & $\begin{array}{l}42 \cdot 6 \\
52 \cdot 5 \\
11 \cdot 4\end{array}$ & $\begin{array}{c}17 \cdot 5^{*} \\
33 \cdot 3^{* *} \\
7 \cdot 9\end{array}$ & $\begin{array}{l}38 \cdot 4 \\
47 \cdot 5 \\
22 \cdot 7\end{array}$ & $\begin{array}{l}13 \cdot 3^{*} \\
27 \cdot 7^{* *} \\
0^{*}\end{array}$ \\
\hline
\end{tabular}

Significant gender differences: ${ }^{*} \mathrm{p}<0.05,{ }^{* *} \mathrm{p}<0.01$.

No significant cohort differences were noted.

†DIP=distal interphalangeal; PIP=proximal interphalangeal; IP=interphalangeal; $\mathbf{M C P}=$ metacarpophalangeal; $\mathrm{CMC}=$ carpometacarpal; $\mathrm{ROM}=$ range of motion.

Table 4 Prevalence (percentage) of radiographic osteoarthritis in women

\begin{tabular}{|c|c|c|c|c|c|}
\hline \multirow[t]{2}{*}{ Foint } & & \multicolumn{2}{|c|}{$\begin{array}{l}79 \text { Year olds (cohort II) } \\
(n=162)\end{array}$} & \multicolumn{2}{|c|}{$\begin{array}{l}85 \text { Year olds (cohort I) } \\
(n=104)\end{array}$} \\
\hline & & Grade 2 & Grades 3-4 & Grade 2 & Grades 3-4 \\
\hline $\begin{array}{l}\text { DIP } \\
\text { PIP } \\
\text { IP I } \\
\text { MCP II-V } \\
\text { MCP I } \\
\text { CMC I } \\
\text { Intracarpal } \\
\text { Radiocarpal } \\
\text { Knee }\end{array}$ & $\begin{array}{l}\text { Left } \\
\text { Right } \\
\text { Left } \\
\text { Right } \\
\text { Left } \\
\text { Right } \\
\text { Left } \\
\text { Right } \\
\text { Left } \\
\text { Right } \\
\text { Left } \\
\text { Right } \\
\text { Left } \\
\text { Right } \\
\text { Left } \\
\text { Right } \\
\text { Left } \\
\text { Right }\end{array}$ & $\begin{array}{l}61 \cdot 3 \\
63 \cdot 8 \\
45 \cdot 0 \\
48 \cdot 1 \\
56 \cdot 3 \\
62 \cdot 5 \\
46 \cdot 3 \\
50 \cdot 0 \\
46 \cdot 9 \\
52 \cdot 5 \\
40 \cdot 0 \\
42 \cdot 1 \\
18 \cdot 2 \\
18 \cdot 9 \\
25 \cdot 0 \\
38 \cdot 1 \\
45 \cdot 6 \\
43 \cdot 7\end{array}$ & $\begin{array}{c}16 \cdot 1 \\
22 \cdot 9 * * \\
9 \cdot 4 \\
8 \cdot 8 \\
8 \cdot 7 \\
13 \cdot 1^{* *} \\
3 \cdot 1 \\
8 \cdot 1^{* *} \\
5 \cdot 0 \\
3 \cdot 8 \\
16 \cdot 3 \\
3 \cdot 8 \\
3 \cdot 7 \\
3 \cdot 1 \\
5 \cdot 4 \\
5 \cdot 0 \\
8 \cdot 0 \\
9 \cdot 5\end{array}$ & $\begin{array}{l}50 \cdot 0 \\
65 \cdot 7 \\
33 \cdot 3 \\
41 \cdot 2 \\
44 \cdot 1 \\
52 \cdot 0 \\
32 \cdot 4 \\
36 \cdot 3 \\
27 \cdot 5 \\
30 \cdot 4 \\
36 \cdot 3 \\
35 \cdot 3 \\
11 \cdot 2 \\
19 \cdot 3 \\
25 \cdot 5 \\
25 \cdot 5 \\
33 \cdot 0 \\
32 \cdot 7\end{array}$ & $\begin{array}{c}22 \cdot 6 \\
19 \cdot 7 \\
9 \cdot 8 \\
5 \cdot 9 \\
3 \cdot 9 \\
6 \cdot 9 * * \\
3 \cdot 9 \\
2 \cdot 9 \\
0 \\
2 \cdot 0 \\
3 \cdot 9 \\
4 \cdot 9 \\
2 \cdot 1 \\
2 \cdot 0 \\
4 \cdot 4 \\
2 \cdot 1 \\
7 \cdot 8 \\
11 \cdot 5\end{array}$ \\
\hline
\end{tabular}

**Significant ( $p<0.01$ ) differences (grades 2-4) between left and right side in DIP, IP I and MCP II-V joints in 79 year olds and in IP I joints in 85 year olds.

Significant $(p<0.001)$ difference (grades $2-4)$ between the two cohorts in wrist and hand joints. tFor abbreviations see table 3 .

Table 5 Preoalence (percentage) of radiographic osteoarthritis in men

\begin{tabular}{|c|c|c|c|c|c|}
\hline \multirow[t]{2}{*}{ Foint } & & \multicolumn{2}{|c|}{$\begin{array}{l}79 \text { Year olds (cohort II) } \\
(n=104)\end{array}$} & \multicolumn{2}{|c|}{$\begin{array}{l}85 \text { Year olds (cohort I) } \\
(n=58)\end{array}$} \\
\hline & & Grade 2 & Grades 3-4 & Grade 2 & Grades 3-4 \\
\hline $\begin{array}{l}\text { DIP } \\
\text { PIP } \\
\text { IP I } \\
\text { MCP II-V } \\
\text { MCP I } \\
\text { CMC I } \\
\text { Intracarpal } \\
\text { Radiocarpal } \\
\text { Knee }\end{array}$ & $\begin{array}{l}\text { Left } \\
\text { Right } \\
\text { Left } \\
\text { Right } \\
\text { Left } \\
\text { Right } \\
\text { Left } \\
\text { Right } \\
\text { Left } \\
\text { Right } \\
\text { Left } \\
\text { Right } \\
\text { Left } \\
\text { Right } \\
\text { Left } \\
\text { Right } \\
\text { Left } \\
\text { Right }\end{array}$ & $\begin{array}{l}55 \cdot 1 \\
69 \cdot 2 \\
35 \cdot 5 \\
43 \cdot 0 \\
44 \cdot 9 \\
54 \cdot 2 \\
33 \cdot 6 \\
45 \cdot 8 \\
55 \cdot 1 \\
57 \cdot 9 \\
41 \cdot 1 \\
42 \cdot 1 \\
9 \cdot 4 \\
10 \cdot 3 \\
40 \cdot 6 \\
36 \cdot 4 \\
38 \cdot 1 \\
34 \cdot 3\end{array}$ & $\begin{array}{c}15 \cdot 0 \\
12 \cdot 2 \\
6 \cdot 6 \\
4 \cdot 7 \\
11 \cdot 2 \\
7 \cdot 4 \\
7 \cdot 5 \\
6 \cdot 5 * * \\
5 \cdot 6 \\
8 \cdot 4 \\
6 \cdot 5 \\
8 \cdot 4^{* *} \\
0 \cdot 9 \\
0 \\
2 \cdot 1 \\
4 \cdot 7 \\
6 \cdot 7 \\
8 \cdot 6\end{array}$ & $\begin{array}{r}55 \cdot 2 \\
48 \cdot 3 \\
32 \cdot 8 \\
27 \cdot 6 \\
46 \cdot 6 \\
37 \cdot 9 \\
22 \cdot 4 \\
27 \cdot 6 \\
24 \cdot 1 \\
35 \cdot 5 \\
24 \cdot 1 \\
20 \cdot 7 \\
5 \cdot 4 \\
5 \cdot 4 \\
26 \cdot 5 \\
22 \cdot 8 \\
20 \cdot 7 \\
20 \cdot 7\end{array}$ & $\begin{array}{r}6 \cdot 9 \\
12 \cdot 1 \\
6 \cdot 1 \\
5 \cdot 1 \\
1 \cdot 7 \\
1 \cdot 7 \\
3 \cdot 4 \\
3 \cdot 4 \\
0 \\
1 \cdot 7 \\
0 \\
1 \cdot 7 \\
0 \\
0 \\
6 \cdot 1 \\
3 \cdot 5 \\
1 \cdot 7 \\
3 \cdot 5\end{array}$ \\
\hline
\end{tabular}

** Significant ( $p<0.01$ ) differences (grades 2-4) between left and right side in MCP II-V and CMC I joints in 79 year olds.

Significant difference (grades 2-4) between the two cohorts in wrist, hand $(p<0.001)$, and knee $(\mathbf{p}<0.01)$ joints.

†For abbreviations see table 3.

joints in 79 year olds $(p<0.05)$ and in knee joints $(p<0.05$ and $<0.01$ for deformity and crepitus respectively) in the two cohorts. In the hands clinical signs of osteoarthritis were common and most prevalent in the DIP, PIP, and MCP I joints in both women and men. Clinical signs of osteoarthritis in the IP I and CMC I joints were rather uncommon and observed in $4-13 \%$ of both men and women.
Table 6 Percentage of subjects with reported joint complaints and radiographic evidence of osteoarthritis in the pooled sample of 160 subjects (61 men, 99 women) at age 79 and 85

\begin{tabular}{lllll}
\hline & \multicolumn{4}{l}{ Radiographic grade } \\
\cline { 2 - 5 } & 0 & 1 & 2 & $3-4$ \\
\hline Hand joints & $\overline{11}$ & 8 & 12 & 29 \\
Knee joints & 6 & 14 & 43 \\
\hline
\end{tabular}

Significant correlation between joint complaints and radiographic osteoarthritis ( $<<0.05$ for hand joints, $p<0.001$ for knee joints, tested for linear trend).

\section{RADIOGRAPHIC OSTEOARTHRITIS}

Osteoarthritis was generally more common on the right side than on the left side $(p<0.01$, paired $t$ test) (tables 4 and 5). For the individual joints the differences between the right and left sides were significant $(p<0.01)$ in DIP, IP I, and MCP II-V joints in 79 year old women, in MCP II-V and CMC I joints in 79 year old men, and in IP I joints in 85 year old women. The prevalence of minimal osteoarthritis (grade 2 ) in wrist and hand joints was $20-70 \%$ and of moderate and severe osteoarthritis (grades 3-4) $0-23 \%$. The DIP and IP I joints were the most affected. In the knee joints grade 2 osteoarthritis was found in $21-46 \%$ and grade $3-4$ osteoarthritis in $2-11 \%$. Women had in general more radiographic osteoarthritis than men $(p<0.001$, ANOVA). Significant differences $(p<0.01)$ were found in the 85 year olds, among whom women had more osteoarthritis in wrist, hand, and knee joints. There was no evidence of a greater prevalence of osteoarthritis in 85 year olds than in 79 year olds. On the contrary, a significantly lower prevalence $(p<0.001)$ of osteoarthritis was observed in wrist and hand joints in both men and women in the 85 year old cohort and in knee joints in 85 year old men $(\mathrm{p}<0.01)$.

ASSOCIATION BETWEEN JOINT COMPLAINTS, CLINICAL SIGNS OF OSTEOARTHRITIS, AND RADIOGRAPHIC OSTEOARTHRITIS

As the joint complaints and clinical signs of osteoarthritis were not significantly different in the two cohorts the 79 and 85 year old groups were pooled to get a larger sample. No significant association was found between joint complaints and clinical findings of osteoarthritis in wrist and hand joints. In the knee joints a significant $(p<0.05)$ correlation was found between joint complaints and findings of deformity, crepitus, and loss of range of movement (data not shown). Furthermore, a significant correlation between joint complaints and radiographic osteoarthritis was found both in hand and knee joints (test for linear trend, $\mathrm{p}<0.05$ and 0.001 respectively) (table 6). Only $29 \%$ of those with grade $3-4$ osteoarthritis in hand joints and $43 \%$ of those with grade $3-4$ osteoarthritis in knee joints reported complaints, however.

The correlation between radiographic osteoarthritis and clinical signs was significant in all joints examined (table 7). As shown in the table, however, clinical signs of osteoarthritis were present without radiographic findings and 
Table 7 Percentage of subjects with clinical signs of osteoarthritis and radiological evidence of osteoarthritis in the pooled sample of 160 subjects (61 men, 99 women) at age 79 and 85)

\begin{tabular}{lrrrl}
\hline foint & \multicolumn{5}{c}{ Radiographic grade } \\
\cline { 2 - 5 } & 0 & 1 & 2 & $3-4$ \\
\hline Hand & 0 & 17 & 24 & $74^{* * *}$ \\
DIP & 16 & 16 & 36 & $33^{* *}$ \\
PIP & 0 & 7 & 12 & $60^{* *}$ \\
IP I & 19 & 33 & 38 & $75^{* * *}$ \\
MCP I & 0 & 2 & 17 & $31^{* * *}$ \\
CMC I & & & & \\
Knee & 12 & 9 & 42 & $90^{* * *}$ \\
Deformity & 25 & 36 & 43 & $55^{*}$ \\
Crepitus & 2 & 3 & 14 & $50^{* * *}$ \\
Limited ROM & 2 & & \\
\hline
\end{tabular}

Significant correlation between clinical signs and radiographic findings of osteoarthritis: ${ }^{*} \mathrm{p}<0.05,{ }^{* *} \mathrm{p}<0.01,{ }^{* * *} \mathrm{p}<0.001$ tested for linear trend.

tFor abbreviations see table 3.

radiographic findings were often present without clinical signs.

\section{Discussion}

There was no indication in this cross sectional comparison of an increasing prevalence of clinical and radiographic osteoarthritis in wrist, hand, and knee joints between 79 and 85 years of age. On the contrary, a lower prevalence of radiographic osteoarthritis (grades 2-4) in wrist and hand joints was noted in 85 year old men and women and in knee joints in 85 year old men. This study confirms the high prevalence of radiographic osteoarthritis in older age groups and that women in general have more osteoarthritis than men. ${ }^{1-8} 1011$

The high prevalence of radiographic osteoarthritis was ascribed to the Kellgren-Lawrence criteria for radiographic reading of osteoarthritis, in which osteoarthritis is defined as grade 2 changes (definite osteophytes) or higher. ${ }^{15}$ There is still no definite answer, however, to the question whether osteophytes are part of the physiological process of aging or an early sign of osteoarthritis. ${ }^{16-18}$ In the previous report ${ }^{7}$ from this population study on the prevalence of joint disorders in the elderly it was predicted that some radiological changes would be found in almost all elderly, and rather restricted criteria for osteoarthritis were used. In our report wider and more generally used criteria ${ }^{15}$ have been implemented, resulting in higher and not directly comparable prevalence figures.

The finding of more osteoarthritis in the right hand than in the left, assuming that most people are right handed, supports previous theories 11920 that overuse may be a cause of osteoarthritis. This conflicts with a recent study of 53-75 year olds in non-physical occupations, ${ }^{21}$ however, which indicated that increased use was not associated with an increased prevalence of osteoarthritis in the dominant hands.

Our criteria for clinical signs of osteoarthritis were arbitrary because no criteria for epidemiological studies of osteoarthritis were available at the time of the investigation. In the recently developed American Rheumatism Association criteria for classification and reporting of knee osteoarthritis ${ }^{22}$ bony tenderness and bony enlargement were included in addition to crepitus- two clinical signs which we did not evaluate. Crepitus was the most common sign of clinical osteoarthritis in this study, but varus and valgus deformity was more often associated with radiological findings.

Hand joints are the most common site of radiographic osteoarthritis-an observation also made in this study. The DIP joints were found to be the most affected joints, which is in agreement with previous studies. ${ }^{14-11}$ In earlier reports the IP I and MCP I joints have been included in the DIP and MCP groups of joints respectively. Bergström et al studied osteoarthritis in the IP I and the MCP I joint separately. ${ }^{7} 10$ They found a higher prevalence of osteoarthritis in the MCP I joint in men at older ages, a result which could not be confirmed in our study when wider criteria for osteoarthritis were used.

Most other earlier studies have shown an increased prevalence of both clinical and radiographic osteoarthritis up to at least age $70 .^{13-6}$ In the previous study on the same population an increase in the prevalence of hand osteoarthritis was noted from 70 to 79 years of age. ${ }^{7}$

Forman et al investigated the prevalence of symptoms and clinical signs of osteoarthritis in the knee joints of 682 elderly subjects aged 60-99 and did not note an increased prevalence with age. ${ }^{2}$ Their study was not population based, however, the subjects were drawn from senior citizen centres and from a population of hospital inpatients, and no radiographs were obtained.

In the Framingham osteoarthritis study 1420 cohort members with ages ranging from 63 to 94 years were subjected to clinical and radiographic examinations of knee joints. ${ }^{3}$ Among this cohort 206 were older than 80 . In contrast with the present population study, there seems to be no evidence that the elderly in the Framingham study were representative for the population at their ages. Radiographic osteoarthritis was reported to increase gradually with age in the Framingham study, and in women this trend was highly significant $(p<0.001)$. Increased mortality has been found in women with radiographic knee osteoarthritis, ${ }^{23}$ which might explain our results. Previous results from this population study ${ }^{7}$ did not show any association between mortality and osteoarthritis, however. It is thus still unclear whether the discrepancy between the results for age related increase in the prevalence of osteoarthritis is due to methodological differences or to differences in the onset of osteoarthritis between different populations.

In population surveys symptoms and clinical findings correlate poorly with radiographic osteoarthritis. $^{324-26}$ It has long been recognised that many subjects have radiological signs of osteoarthritis without any symptoms. Lawrence et al found a correlation between severity (grades 3-4) of osteoarthritis and joint pain, but no significant correlation when all degrees (grades 1-4) of radiographic osteoarthritis were included. ${ }^{27}$ In a follow up study of subjects aged $55-74^{23}$ only $44 \%$ of those reporting knee pain had radiographic osteoarthritis grades 2-4. There was a significant association between pain 
and radiographic severity, however. In the Framingham osteoarthritis study $30 \%$ of those with grades 3-4 osteoarthritis in the knee joints had symptoms. In the Tecumseh osteoarthritis study ${ }^{21}$ an association between pain and radiographic osteoarthritis was found both in hand and knee joints. We also found a correlation between joint complaints and radiographic osteoarthritis, but only 29 and 43\%, respectively, of those with grades 3-4 osteoarthritis reported symptoms. Furthermore, almost 50\% of those with radiological changes had no clinical signs of osteoarthritis and clinical signs were often present without radiological findings.

These results show that increasing age does not necessarily lead to an increase of joint symptoms, clinical signs of osteoarthritis, or radiographic evidence of osteoarthritis. Our study was cross sectional, however, and we cannot exclude the possibility of a cohort difference. Our study and previous studies of the elderly in Göteborg did not indicate that the prevalence of knee joint osteoarthritis increases with age of the cohort between 70 and 85 years of age in this population. This study showed no increase of osteoarthritic symptoms, signs, or radiological changes of osteoarthritis between the 79 and 85 year old cohorts. The discrepancies between radiographic osteoarthritis, joint complaints, and clinical findings emphasise that our understanding of the processes affecting symptoms from joints is still poor. Longitudinal studies and comparisons between populations are important to elucidate further the role of age in osteoarthritis in the elderly.

We thank Professor Hans Valkenburg, department of epidemiology, University of Rotterdam, The Netherlands, for valuable advice, assistance and participation in the radiographic interobserver study.

Supported by grants from The Swedish Ministry of Health and Supported by grants from The Swedish Ministry of Health and
Social Affairs, Commissions for Social Research. The Swedish Social Affairs, Commissions for Social Research, The Swedish Medical Research Council, The Gothenburg Medical Services of
Administration, and Wilhelm and Martina Lundgren's FoundaAdmin.

1 Lawrence J S. Generalized osteoarthrosis in a population sample. Am $\mathcal{F}$ Epidemiol 1969; 90: 381-9.

2 Forman M, Malamet R, Kaplan D. A survey of osteoarthritis of the knee in the elderly. $\mathcal{F}$ Rheumatol 1983; 10: 282-7.

3 Felson D T, Nailmark A, Andersson J, Kazis L, Castellini W, Meenan R F. The prevalence of knee osteoarthritis in W, Meenan R F. The prevalence of knee ost
the elderly. Arthritis Rheum 1987; 30: 914-8.

4 National Center for Health Statistics. Osteoarthritis in adults by selected demographic characteristics: United States 1960-1962. Vital Health Stat [2] 1966: No 20.

5 National Center for Health Statistics. Basic data on arthritis: knee, hip and sacroiliac joints in adults aged 25-74 years, United States, 1971-1975. Vital Health Stat [11] 1979: No 213.

6 Mikkelsen W M, Duff I F, Dodge H D. Age-specific prevalence of radiographic abnormalities of the joints of the Tecumseh, Michigan, community health area, 1962-1965. Tecumseh, Michigan, community health area,

7 Bergström G, Bjelle A, Sundh V, Svanborg A. Joint disorders at ages 70,75 and 79 years-a cross-sectional comparison. $B r \mathcal{F}$ Rheumatol 1986; 25: 333-41.

8 Saase van J L C M, Romunde L K J, Cats A, Vandenbroucke J P, Valkenburg H. Epidemiology of osteoarthritis: Zoetermeer survey, comparison of radiological osteoarthritis in a Dutch population with 10 other populations. Ann Rheum Dis 1989; 48: 455-60.

9 Peyron J G. Epidemiological aspects of osteoarthritis. Scand $\mathcal{F}$ Rheumatol 1989; (suppl 77): 29-33.

10 Bergström G, Bjelle A, Sorensen L B, Sundh V, Svanborg A Prevalence of rheumatoid arthritis, osteoarthritis, and Prevalence of rheumatoid arthritis, osteoarthritis, and

11 Bergström G, Bjelle A, Sorensen L B, Sundh V, Svanbor A. Prevalence of symptoms and signs of joint impairment at A. Prevalence of symptoms and signs of joint impair

12 Rinder L, Roupe S, Steen B, Svanborg A. Seventy-year-old people in Gothenburg: a population study in an industrialized Swedish city. I. General presentation of the study. Acta Medica Scandinavica 1977; 198: 397-407.

13 Svanborg A. Seventy-year-old people in Gothenburg: a population study in an industrialized Swedish city. II. General presentation of social and medical conditions. Acte Medica Scandinavica Supplement 1977; 611: 5-37.

14 Svanborg $A$. The health of the elderly population: results from the longitudinal studies with age-cohort comparisons. Research and the ageing population. Chichester: Wiley, 1988: Research and the ageing population. Chichester:

15 Kellgren J H. The epidemiology of chronic rheumatism. Atlas of standard radiographs. Vol 2. Oxford: Blackwell Scientific, 1963.

16 Hernborg J, Nilson B E. The relationship between osteophytes in the knee joint, osteoarthritis and ageing. Acto Orthop Scand 1974; 44: 69-74.

17 Danielsson L, Hernborg J. Clinical and roentgenologic study of knee joints with osteophytes. Clin Orthop 1970; 69: 302-12.

18 Brandt K D, Fifes R S. Aging in relation to the pathogenesis of osteoarthritis. Clin Rheum Dis 1986; 12: 117-30.

19 Acheson R M, Yick-Kwong Chan, Clemett A R. New Haven survey of joint diseases. XII. Distribution of symptoms of survey of joint diseases. XII. Distribution of symptoms of osteoarthritis in the hand with refen

20 Lane L, Bloch D, Jones H, Simpson U, Fries J. Osteoarthritis in the hand: a comparison of handedness and hand use. 7 Rheumatol 1989; 16: 537-42.

21 Carman W. Factors associated with pain and osteoarthritis in the Tecumseh community health study. Semin Arthritis Rhew 1989; 18: 10-13.

22 Altman R, Asch E, Bloch D, et al. Development of criteria for the classification and reporting of osteoarthritis. Arthritis R the classification and

23 Hochberg M, Lawrence R C, Everett D F, CornoniHuntley J. Epidemiological associations of pain in osteoarthritis of the knee. Data from the national health and arthritis of the knee. Data from the national health and
nutrition examination survey and the national health and nutrition-1 epidemiologic follow-up survey. Semin Arthritis Rherum 1989; 2 (suppl 4): 2-4.

24 Davis M A. Epidemiology of osteoarthritis. Clin Geriatr Med 1988; 4: 241-55.

25 Bjelle A. On the heterogeneity of osteoarthritis. Clin Rheumatol 1983; 2: 111-3.

26 Valkenburg $\mathbf{H}$. Clinical versus radiological osteoarthritis in the general population. In: Peyron J G, ed. Epidemiology of osteoarthritis. Rueil-Malmaison: Geigy, 1981: 53-8.

27 Lawrence J S, Bremner J M, Bier F. Osteoarthritis. Prevalence in population and relationship between Prevalence in population and relationship between
symptoms and $x$-ray changes. Ann Rhewon Dis 1966; 25: symptom. 